\title{
Klasifikasi Penyakit Hipertensi Dan Diabetes Berbasis Web Pada Klinik Pratama Rumkitban 01.08.03 Batam
}

\author{
Mira Chandra Kirana ${ }^{1 *}$, Michel $\mathrm{K}^{2 * *}$ \\ * Teknik Informatika, Politeknik Negeri Batam \\ ** Teknik Multimedia Jaringan, Politeknik Negeri Batam \\ mira@polibatam.ac.id ${ }^{1}$, michaeloke14@gmail.com ${ }^{2}$
}

\begin{tabular}{l} 
Article Info \\
\hline Article history: \\
Received 09-06-2021 \\
Revised 20-07-2021 \\
Accepted 22-07-2021 \\
\hline
\end{tabular}

Keyword:

Algoritma C45,

Classification,

Diabetes,

Hypertension,

Tree Decision.

\begin{abstract}
The management of outpatient medical records at the Rumkitban Primary Clinic 01.08.03 Batam is still manual and causes many limitations and problems. This problem resulted in the inability of the clinic to run the Chronic Disease Treatment Program (PROLANIS) organized by BPJS-Health. The purpose of the study is to facilitate data processing and then from that data it can be used to classify hypertension and diabetes then the results of the classification are displayed in graphical form. This study discusses 2 diseases, namely hypertension and diabetes. The system uses the C45 Tree Decision Algorithm for automatic data processing. The attributes used are glucose, diastolic, systolic, insulin, and age to support the decision-making system. The system can make a decision whether the patient has hypertension, diabetes or not. The results of this study are the accuracy of classification accuracy in the system for hypertension shows $16.667 \%$ accuracy and $83.333 \%$ accuracy is not correct, then the calculation of diabetes classification accuracy shows $96.667 \%$ accuracy, and $3.333 \%$ accuracy is incorrect. This system is integrated with Mysql database to store the results.
\end{abstract}

This is an open access article under the CC-BY-SA license.

\section{Pendahuluan}

Klinik Pratama Rumkitban 01.08.03 Batam merupakan instansi militer angkatan darat yang bergerak di bidang kesehatan, dimana fungsi utamaya adalah memberikan pelayanan kesehatan dan balai pengobatan kepada TNI, PNS dan keluarga TNI dan PNS. Klinik Pratama Rumkitban 01.08.03 Batam sebagai salah satu institusi pelayanan kesehatan umum, juga menerima pasien umum berobat dari masyarakat umum dan pasien BPJS Kesehatan, sehingga membutuhkan sebuah sistem informasi yang tingkat akurat dan h1 tinggi, serta memadai untuk meningkatkan pelayanan Klinik Pratama Rumkitban kepada pasien dan lingkungan terkait. Unit yang menyediakan informasi penting untuk pimpinan dalam mengambil suatu keputusan dalam meningkatkan pelayanan terhadap pasien adalah unit rawat jalan. Unit rawat jalan setiap harinya melakukan aktifitas pelayanan terhadap pasien yang mendapatkan pelayanan pengobatan dan diagnosa oleh dokter.
Pengelolaan penyakit kronis (Prolanis) [1] yaitu hipertensi dan diabetes dari BPJS-Kesehatan ini belum berjalan sepenuhnya dikarenakan kurangnya SDM, pendataan peserta prolanis yang belum jelas, dan manajemen rekam medis pasien yang kurang baik. Berdasarkan masalah yang timbul sehigga muncul ide untuk membuat sebuah aplikasi agar berkurangnya masalah yang ada, maka dari penelitian ini akan segera dibuat sistem untuk mengklasifkasi pasien penyakit kronis berbasis web agar nantinya dapat mendata peserta prolanis dan melakukann pemantauan peserta prolanis yang terdapat pada Rumkitban 01.08.03 Batam. Untuk menangani permasalahan tersebut perlu adanya pengembangan sistem informasi rekam medis rawat jalan di Klinik Pratama Rumkitban 01.08.03 Batam.

Penelitian sebelumnya yang di lakukan oleh [2] membuktikan seluruh variabel MMUST berpengaruh terhadap kesuksesan implementasi RME dengan nilai R2 kepuasan informasi 0,394; harapan kinerja 0,292; kepuasan keseluruhan 0,602; manfaat keseluruhan 0,444; dan sikap 0,655. Nilai Goodness of Fit (GoF) sebesar 0.5777, sehingga 
dapat disimpulkan model penelitian ini secara substansial merepresentasikan hasil penelitian. Dengan dilakukan penelitian ini dapat membantu klinik dalam pengelohan data secara akurat dan tepat. Dengan memiliki data yang akurat dan tepat klinik mampu menjalan program pengelohan penyakit kronis yang diselengarahkan oleh BPJS-Kesehatan.

Penelitian sebelumnya yang dilakukan oleh [3] menunjukan bahwa dengan mengubah rekam medis dan banyaknya data medis yang tersedia kedalam digitalisasi akan menjadi area potensi penelitian yang luas dan berguna bagi bidang kesehatan maupun bidang lainnya. Maka Penelitian yang dilakukan menggunakan web agar memudahkan dalam mengelolah data karena sistem untuk mengakses, memanipulasi, dan mengunduh dokumen yang terdapat dalam komputer [4] sangat terorganisir dengan baik dan tercatat dengan rapi dalam sistem. Oleh sebab itu dibutuhkan sebuah web server pada penilitian ini agar berguna untuk pengolahan dan pengujian data yang sangat banyak.

Rekam medis ini juga di didukung dengan fitur untuk mengklasifikasi penyakit hipertensi dan diabetes sesuai dengan program dari BPJS-Kesehatan mengelolah data pasien hipertensi dan diabetes. Penelitian sebelumnya yang dilakukan oleh [5] menunjukan bahwa sebuah sistem dapat memberikan informasi tentang diagnosa awal penyakit diabetes kepada masyarakat agar dapat melakukan tindakan awal atau pencegahan terhadap penyakit diabetes militus. Dalam mengelolah data tersebut sistem di didukung dengan beberapa atribut yang di inputkan oleh dokter.

Pada penelitina ini menggunakan beberapa atribut seperti glukosa, diastole, sistol, insulin, dan usia. Menggunakan algoritma c45 sebagai pengolahan datanya untuk menciptakan sebuah pohon keputusan yang akan di gunakan oleh sistem untuk mengklasifikasi penyakit hipertensi dan diabates. Karena pada penelitian sebelumya yang dilakukan oleh [6] diperoleh bahwa performa tertinggi dalam mengklasifikasi dicapai ketika algoritma IDE3 menggunakan 5 atribut yaitu gpost, glun, upost, urin dan actn. Dimana kelima atribut tersebut diperoleh menggunakan algoritma Correlation based Feature Selection (CFS) dengan nilai rata-rata akurasi sebesar 84.77, nilai ratarata sensitifity sebesar 87.18 , dan nilai rata-rata specificity sebesar 82.37. dengan menggunakan 5 atribut juga sehingga di penelitian ini dapat menghasilkan tingkat ketepatan klasifikasi penyakit yang akurasinya tinggi juga. dasar algoritma $\mathrm{C} 4.5$ adalah pohon keputusan. Pada dasarnya Algoritma data mining C4.5 merupakan salah satu algoritma yang digunakan untuk melakukan klasifikasi atau segmentasi atau pengelompokan yang bersifat prediktif. [7]

Maka dari Penelitian ini diharapkan Menyediakan sebuah solusi pencatatan rekam medis secara tepat dan akurat, kemudian data yang dihasilkan dapat digunakan untuk diklasifikasi menjadi penyakit hipertensi dan diabetes dan ditampilkan hasil dalam bentuk grafik. Dalam perancangan dan pengembangan serta dalam penerapannya menyesuaikan dengan kebutuhan dan perkembangan teknologi terkini yang relevan.

\section{Metode Penelitian}

\section{A. Alur Penelitian}

Untuk mencapai tujuan yang diharapkan dan sesuai dengan latar belakang, dilakukan beberapa tahapan yaitu antara lain.

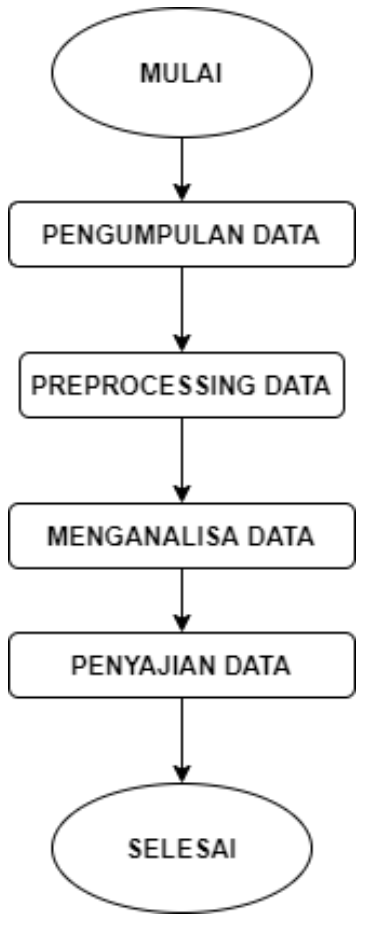

Gambar 1. Alur penelitian

Gambar 1 mengambarkan seluruh tahap yang ada dalam proses penelitian. Penelitian yang dilakukan terbagi menjadi 3 tahapan yaitu mengumpulkan data, preprocessing data, dan menganalisa data. pada tahap awal ini menggumpulkan data langkah yang dilakukan yaitu mengambil data pasien penyakit hipertensi dan diabetes dari rekam medis Klinik Pratama Rumkitban 01.08.03 Batam kemudian dilanjutkan dengan tahap preprocessing data yang dilakukan adalah data cleaning, data integration, data transformation, dan data reduction. Pada data cleaning digunakan untuk melengkapi, menghilangkan data yang tidak lengkap, dam menghaluskan atau meniadakan data noisy, ada juga memperbaiki data yang tidak konsisten (berubah-berubah).

Pada data integration berguna untuk mengabungkan data dari beberapa database kedalam satu database baru. Pada data transformation berguna untuk mengubah data agar berbentuk yang sesuai proses mining. Pada data reduction berguna untuk mengurangkan ukuran data kemudian menghasilkan analisis yang sama.

Dimana pada tahap ini menghasilkan data yang memiliki kualitas baik atau data akurat untuk dilakukan proses mining pada sistem, petugas mengelompokkan data menjadi 2 yaitu data training dan testing. Pada data training akan diproses terlebih dahulu oleh algoritma C4.5 untuk menghasilakn sebuah pohon keputusan/ rule untuk sistemnya. Yang nantinya akan digunakan untuk prediksi kelas data baru yang 
belum pernah ada. Kemudian untuk data testing digunakan untuk mengukur sejauh mana tingkat keberhasil sistem melakukan klasifikasi dengan akurat dan tepat.

Lalu dilanjutkan tahapan menganalisa merupakan tahapan akhir yang dimana data akan dimasukan kedalam aplikasi kemudian sistem melakukan klasifikasi dengan sendirinya dari pohon keputusan yang sudah di dapatkan dari hasil mining menggunakan algoritma C4.5, sehingga sistem menghasilkan klasifikasi penyakit.

1) Pengumpulan Data: data yang digunakan berasal dari data rekam medis Klinik Pratama Rumkitban 01.08.03 Batam. Atribut-atribut dalam sistem ini menggunakan diantaranya: usia, kadar glukosa darah, tekanan darah, insulin.

2) Preprocessing Data: pada gambar 2 mengambarkan tahapan preprocessing data yaitu dengan melakukan preprocessing terhadap data hasil rekam medis dan kemudian dilanjukan dengan mengelompokkan data menjadi 2 bagian yaitu data training dan data testing. Pada Data training digunakan oleh algoritma decision tree C4.5 untuk membentuk sebuah pohon keputusan / rule untuk system nantinya. Pada data testing untuk mengukur sejauh mana tingkat keberhasil sistem melakukan klasifikasi dengan akurat dan tepat.

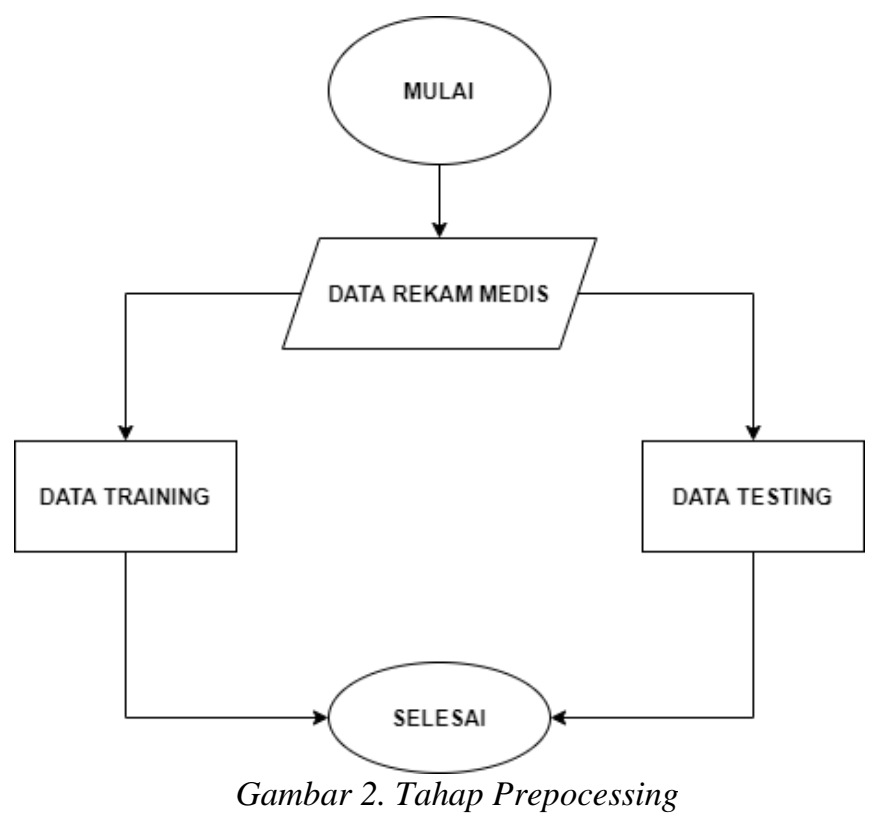

Gambar 2. Tahap Prepocessing
3) Analisa Data

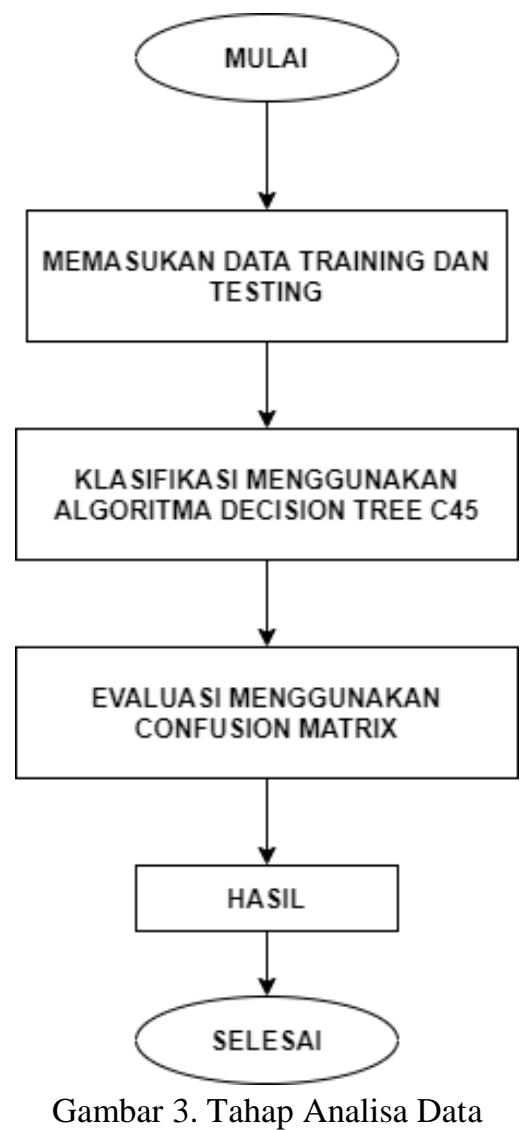

Gambar 3 mengambarkan tahap menganalisa yang dimulai dari tahap memasukan data training dan data testing ke dalam aplikasi, tahap selanjutnya adalah tahap untuk melakukan klasifikasi yang diproses oleh algoritma Decision Tree C4.5 [8].

Entropi $(\mathrm{S})=\sum_{i=1}^{k}-$ pi $k i=1 \log 2 p i$

Keterangan:

- S: Himpunan (dataset) kasus

- $\quad \mathrm{k}$ : Banyaknya partisi S

- Pi: Probabilitaas yang didapat dari Sum(Ya) atau Sum(Tidak) dibagi total kasus

Setelah mendapatkan entropi dari keseluruhan kasus, lakukan analisis pada setiap atribut dan nilai-nilainya dan hitung entropinya. Langkah berikutnya yaitu dengan menghitung Gain, rumus daripada Gain adalah sebagai berikut: [8]

$\operatorname{Gain}(\mathrm{A})=$ Entropi $(\mathrm{S})-\sum_{i=1}^{k} \frac{|S i|}{|S|} x$ Entropi (Si.)

Keterangan:

- S: himpunan kasus

- A: atribut

- $n$ : jumlah partisi atribut A 
- $\quad|\mathrm{Si}|:$ jumlah kasus pada partisi ke-i

- $|\mathrm{S}|$ : jumlah kasus dalam $\mathrm{S}$

Setelah itu akan system akan menghasilkan sebuah pohon keputusan yang akan digunakan untuk menghasilkan klasifikasi penyakit hipertensi dan diabetes. Kemudian dilanjutkan Tahapan untuk mengevaluasi hasil klasifikasi data yang dilakukan sistem untuk memperkirakan hasil klasifikasi yang dilakukan benar atau salah. Sistem juga dapat menghitung tingkat akurasi ketepatan klasifikasi dengan menggunakan confusion matrix. yang dimana contohnya terdapat pada table 1

TABLE 1.

MOdEL CONFUSION MATRIX

\begin{tabular}{|c|c|c|}
\hline Kelas & Terklasifikasi Positif & Terklasifikasi Negatif \\
\hline Positif & TP (True Positive) & FN (False Negative) \\
\hline Negatif & FP (False Positive) & TN (True Negative) \\
\hline
\end{tabular}

$$
\begin{aligned}
& \text { Akurasi }=\frac{T P+T N}{T P+T N+F P+F N} \star 100 \% \\
& \text { Presisi }=\frac{T P}{F P+T P} \star 100 \% \\
& \text { Recall }=\frac{T P}{F N+T P} \star 100 \%
\end{aligned}
$$

Keterangan:

- TP adalah True Positive, yaitu jumlah data positif yang terklasifikasi dengan benar oleh sistem.

- TN adalah True Negative, yaitu jumlah data negatif yang terklasifikasi dengan benar oleh sistem.

- FN adalah False Negative, yaitu jumlah data negatif namun terklasifikasi salah oleh sistem.

- FP adalah False Positive, yaitu jumlah data positif namun terklasifikasi salah oleh sistem

Tahap yang terakhir yaitu mendapatkan prediksi penyakit diabetes dan hipertensi dari hasil klasifikasi tersebut.

\section{4) Penyajian Dato}

Tabel 2 merupakan data yang dikumpulkan, setelah itu diletakkan di dalam sebuah database yang nantinya akan dilakukan preprocessing agar menghasilkan data yang sesuai untuk proses training dan testing.
TABLE 2

PENYAJIAN DATA

\begin{tabular}{|c|c|c|c|c|c}
\hline $\begin{array}{c}\text { Kadar } \\
\text { Gula }\end{array}$ & DIASTOL & SISTOL & $\begin{array}{c}\text { Kadar } \\
\text { Insulin }\end{array}$ & Usia & Kelas \\
\hline 148 & 72 & 35 & 0 & 50 & Diabetes \\
\hline 85 & 66 & 29 & 0 & 31 & $\begin{array}{c}\text { Tidak Diabetes dar } \\
\text { tidak Hipertensi }\end{array}$ \\
\hline 183 & 64 & 0 & 0 & 32 & $\begin{array}{c}\text { Diabetes dan tidak } \\
\text { hipertensi }\end{array}$ \\
\hline 89 & 66 & 23 & 94 & 21 & $\begin{array}{c}\text { Tidak Diabetes dar } \\
\text { tidak Hipertensi }\end{array}$ \\
\hline 137 & 40 & 35 & 168 & 33 & $\begin{array}{c}\text { Diabetes dan tidak } \\
\text { Hipertensi }\end{array}$ \\
\hline 116 & 74 & 0 & 0 & 30 & $\begin{array}{c}\text { Tidak Tidak } \\
\text { Diabetes dan tidak } \\
\text { Hipertensi }\end{array}$ \\
\hline 78 & 50 & 32 & 88 & 26 & $\begin{array}{c}\text { Diabetes dan tidak } \\
\text { Hipertensi }\end{array}$ \\
\hline 115 & 0 & 0 & 0 & 29 & $\begin{array}{c}\text { Tidak Diabetes dar } \\
\text { tidak Hipetensi }\end{array}$ \\
\hline 197 & 70 & 45 & 543 & 53 & $\begin{array}{c}\text { Diabetes dan tidak } \\
\text { Hipertensi }\end{array}$ \\
\hline 125 & 96 & 0 & 0 & 54 & $\begin{array}{c}\text { Diabetes dan } \\
\text { Hipertensi }\end{array}$ \\
\hline
\end{tabular}

Sumber: Rekam Medis Klinik Pratama Rumkitban 01.08.03 Batam)

\section{B. Deskripsi Umum Sistem}
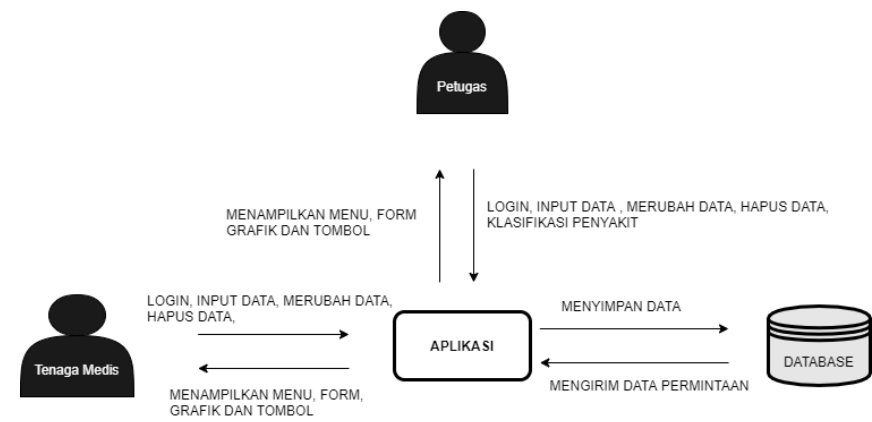

Gambar 2. Deskripsi umum sistem

Gambar 4 deskripsi umum sistem yang akan dirancang,

Sistem aplikasi diatas meliputi:

1) Pasien melakukan pendaftaran berobat melalui Petugas

2) Petugas mendaftarkan pasien dengan login ke dalam aplikasi dan menginput data pasien, Petugas memiliki hak ases untuk menginput, mengupdate, mendelete data pasien, jika sudah selesai di daftarkan petugas memberikan nomor antrian.

3) Tenaga medis memberikan pelayanan kesehatan atau pun tindakan medis terhadap pasien, setelah itu menginputkan tindakan, diagnosa, dan obat kedalam aplikasi. Tenaga medis hanya di berikan hak ases menginput data berobat, mengubah data berobat, memeriksa data pasien, memeriksa hasil klasifikasi penyakit hipertensi dan diabetes kemudian dapat memeriksa riwayat berobat pasien. 
4) Petugas memiliki hak ases mengelola user, data kunjungan sakit, daftar kunjungan peserta prolanis, dan dapat mencetak laporan. Kemudian petugas dapat mengklasifikasi pasien penyakit kronis.

\section{Use Case Diagram}

Pada gambar 5 Use Case Diagram menjelaskan bahwa user melakukan login terlebih dahulu untuk dapat mengelola data user, mengelola data pasien, mengelola data dokter, mengelola data rekam medis, memeriksa riwayat, memriksa laporan dan mengklasifikasi penyakit hipertensi dan diabetes.

Lampiran I

Gambar 3. Use case diagram sistem

\section{Activity Diagram}

Gambar 6 menjelaskan tentang Activity mengklasifikasi penyakit hipertensi dan diabetes:

Diagram

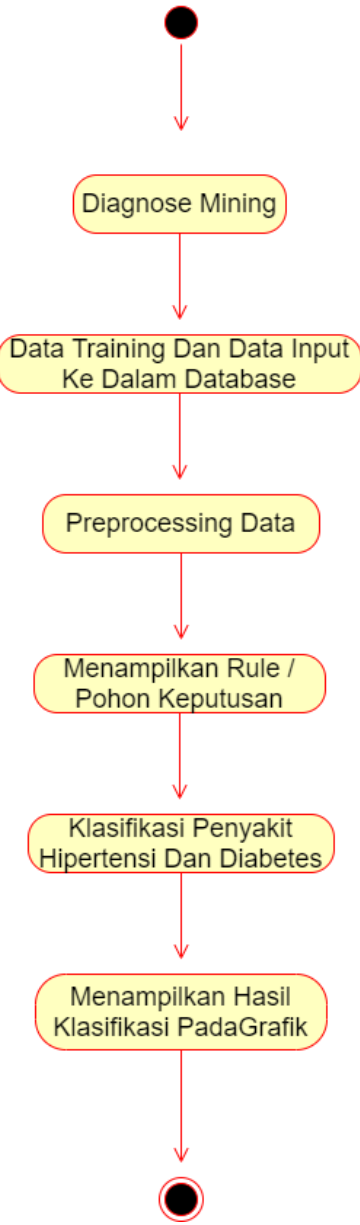

Gambar 4. Activity Diagram klasifikasi penyakit

\section{E. ER-Diagram}

Pada gambar 7 menjelaskan tentang hubungan antar entitas pada sistem dan uji data mining.

\section{Lampiran II}

\section{Gambar 5. ER-Diagram sistem}

\section{HaSil dan PEMBahasan}

Metode yang dipakai dalam penelitian ini adalah algoritma klasifikasi dengan Algoritma Decision Tree yang digunakan untuk melakukan klasifikasi penyakit hipertenis dan diabetes pada data yang ada di sistem. Untuk mendapatkan kinerja algoritma klasifikasi ini menggunakan dataset tersedia pada rekam medis klinik pratama rumkitban 01.08.03 Batam. Dataset yang digunakan memiliki 5 atribut terdiri dari data nominal dan numerik. Kelas data sasaran adalah hipertensi, tidak hipertensi, diabetes dan tidak diabetes. Sistem ini terdiri dari beberapa tahap yaitu preprocessing untuk menghilangkan data - data yang noisy ataupun redudansi, selanjutnya melakukan klasifikasi dengan Algoritma Decision tree C45. Setelah itu dilakukan evaluasi dengan confusion matrix.

\section{A. Preprocessing Data}

Pada proses ini adalah mempersiapkan data yang berkualitas baik untuk diproses data mining yang akan diolah oleh algoritma C45, Tree desicion dan proses testing menggunakan confusion matrix. Preprocessing data ini dilakukan oleh sistem karena pada sistem telah di tanamkan algoritma c45 sehingga sistem otomatis melakukan preprocessing dengan sendirinya. Pada Tabel 3 dan Tabel 4 merupakan tabel data training yang telah melalui proses preprocessing dari data rekam medis klinik pratama Rumkitban 01.08.03 Batam. Data training ini diproses menggunakan algoritma C45 dan Tree Decision. Proses preprocessing data yang dilakukan pada sistem ini adalah merubah data kosong dengan rata-rata data per variable dan mengelompokkan data-data kedalam beberapa kelas.

Adapun pengelompokan data untuk masing-masing variable ini berdasarkan Kemenkes RI tahun 2014 tentang hipertensi [9] dan Kemenkes RI tahun 2019 tentang diabetes [10] sebagai berikut:

- Glukosa $=<=100,>100,<=120,>120,<=140,>140$

- $\quad$ Diastol $=<=70,>70,<=80,>80,<=90,>90$,

- Sistol $=<=110,>110,<=120,>120,<=130,>130$

- Insulin $=<=200,>200,<=300,>300,<=400,>400$

- Usia $=<=17,>17,<=25,>25,<=36,>36,<=56,>56$

- Kelas $=$ Hipertensi, tidak hipertensi, Diabetes, tidak diabetes

Tabel 3 merupakan sebuah data training yang berisi data pasien yang menderita penyakit hipertensi yang didapat dari Klinik Pratama Rumkitban 01.08.03 Batam dan telah melalui proses prepocesing sehingga data dapat di proses oleh sistem dengan algoritma $\mathrm{C} 45$. 
TABEL 3

DATA PENYAKIT HiPeRTENSI SETELAH PREPROCESSING

\begin{tabular}{|c|c|c|c|c|c|c|}
\hline $\begin{array}{l}\text { Nama } \\
\text { Pasien }\end{array}$ & $\begin{array}{l}\text { Gluk } \\
\text { osa }\end{array}$ & $\begin{array}{l}\begin{array}{l}\text { Diast } \\
\text { ol }\end{array} \\
\end{array}$ & $\begin{array}{l}\text { Sist } \\
\text { ol }\end{array}$ & $\begin{array}{l}\text { Insuli } \\
\text { n }\end{array}$ & Usia & Kelas \\
\hline 1 & 100 & 80 & 130 & 200 & 64 & hipertensi \\
\hline 2 & 100 & 80 & 120 & 200 & 57 & tidak \\
\hline 3 & 100 & 90 & 120 & 200 & 59 & tidak \\
\hline 4 & 100 & 90 & 130 & 200 & 66 & hipertensi \\
\hline 5 & 100 & 80 & 120 & 200 & 53 & tidak \\
\hline 6 & 100 & 85 & 121 & 200 & 19 & tidak \\
\hline 7 & 100 & 70 & 115 & 200 & 31 & tidak \\
\hline 8 & 100 & 80 & 110 & 200 & 52 & tidak \\
\hline 9 & 100 & 73 & 122 & 200 & 44 & tidak \\
\hline 10 & 100 & 88 & 118 & 200 & 34 & tidak \\
\hline 11 & 100 & 86 & 123 & 200 & 35 & tidak \\
\hline 12 & 100 & 80 & 109 & 200 & 49 & tidak \\
\hline 13 & 100 & 70 & 135 & 200 & 62 & hipertensi \\
\hline 14 & 100 & 80 & 133 & 200 & 41 & hipertensi \\
\hline 15 & 100 & 90 & 132 & 200 & 52 & hipertensi \\
\hline 16 & 115 & 85 & 130 & 200 & 64 & hipertensi \\
\hline 17 & 123 & 77 & 113 & 240 & 65 & tidak \\
\hline 18 & 135 & 85 & 90 & 231 & 39 & tidak \\
\hline 19 & 100 & 90 & 130 & 210 & 62 & hipertensi \\
\hline 20 & 125 & 80 & 125 & 213 & 53 & tidak \\
\hline 26 & 100 & 85 & 121 & 200 & 19 & tidak \\
\hline 27 & 100 & 70 & 115 & 200 & 31 & tidak \\
\hline 28 & 100 & 80 & 110 & 200 & 52 & tidak \\
\hline 29 & 100 & 73 & 122 & 200 & 44 & tidak \\
\hline 30 & 100 & 88 & 118 & 200 & 34 & tidak \\
\hline 31 & 100 & 86 & 123 & 200 & 35 & tidak \\
\hline 32 & 100 & 80 & 109 & 200 & 49 & tidak \\
\hline 33 & 100 & 70 & 135 & 200 & 62 & hipertensi \\
\hline 34 & 100 & 80 & 133 & 200 & 41 & hipertensi \\
\hline 35 & 100 & 90 & 132 & 200 & 52 & hipertensi \\
\hline 36 & 115 & 85 & 130 & 200 & 64 & hipertensi \\
\hline 37 & 123 & 77 & 113 & 240 & 65 & tidak \\
\hline 38 & 135 & 85 & 90 & 231 & 39 & tidak \\
\hline 39 & 100 & 90 & 130 & 210 & 62 & hipertensi \\
\hline 40 & 125 & 80 & 125 & 213 & 53 & tidak \\
\hline 41 & 139 & 94 & 133 & 230 & 39 & hipertensi \\
\hline 42 & 80 & 75 & 108 & 200 & 28 & tidak \\
\hline 43 & 80 & 80 & 120 & 200 & 20 & tidak \\
\hline 44 & 80 & 90 & 135 & 200 & 40 & hipertensi \\
\hline 45 & 85 & 91 & 133 & 200 & 67 & hipertensi \\
\hline 46 & 80 & 91 & 132 & 200 & 52 & hipertensi \\
\hline 47 & 125 & 88 & 125 & 240 & 61 & tidak \\
\hline 48 & 80 & 95 & 134 & 200 & 62 & hipertensi \\
\hline 49 & 88 & 95 & 135 & 200 & 46 & hipertensi \\
\hline 50 & 100 & 94 & 134 & 200 & 35 & hipertensi \\
\hline 51 & 103 & 99 & 136 & 200 & 38 & hipertensi \\
\hline 52 & 135 & 100 & 136 & 245 & 61 & hipertensi \\
\hline 53 & 132 & 102 & 133 & 210 & 51 & hipertensi \\
\hline 54 & 140 & 95 & 100 & 241 & 64 & tidak \\
\hline 55 & 130 & 80 & 133 & 222 & 60 & tidak \\
\hline 56 & 132 & 80 & 132 & 210 & 58 & hipertesi \\
\hline 57 & 135 & 95 & 135 & 200 & 55 & hipertensi \\
\hline 58 & 145 & 85 & 115 & 200 & 62 & tidak \\
\hline 59 & 80 & 96 & 136 & 200 & 45 & hipertensi \\
\hline 60 & 136 & 85 & 96 & 200 & 57 & tidak \\
\hline 61 & 85 & 95 & 133 & 200 & 50 & hipertensi \\
\hline 62 & 125 & 85 & 115 & 200 & 65 & hipertensi \\
\hline 63 & 100 & 102 & 140 & 200 & 52 & hipertensi \\
\hline 64 & 102 & 98 & 135 & 200 & 43 & hipertensi \\
\hline 65 & 105 & 95 & 133 & 200 & 51 & hipertensi \\
\hline 66 & 100 & 95 & 131 & 200 & 66 & hipertensi \\
\hline 67 & 90 & 90 & 131 & 200 & 45 & hipertensi \\
\hline
\end{tabular}

\begin{tabular}{|l|l|l|l|l|l|l|}
\hline 68 & 135 & 85 & 120 & 235 & 52 & tidak \\
\hline 69 & 135 & 91 & 135 & 200 & 63 & hipertensi \\
\hline 70 & 139 & 94 & 133 & 230 & 39 & hipertensi \\
\hline 71 & 100 & 90 & 125 & 200 & 38 & hipertensi \\
\hline 72 & 100 & 85 & 115 & 200 & 61 & hipertensi \\
\hline 73 & 120 & 81 & 130 & 199 & 65 & hipertensi \\
\hline 74 & 120 & 90 & 129 & 200 & 52 & hipertensi \\
\hline
\end{tabular}

Table 4 merupakan sebuah data training yang berisi data pasien yang menderita penyakit diabetes militus yang didapat dari Klinik Pratama Rumkitban 01.08.03 Batam dan telah melalui proses prepocesing sehingga data dapat di proses oleh sistem dengan algoritma c45.

TABEL 4

Data Penyakit Diabetes Setelah PREPRocessing

\begin{tabular}{|c|c|c|c|c|c|c|}
\hline $\begin{array}{c}\text { Nama } \\
\text { Pasien }\end{array}$ & Glukosa & Diastol & Sistol & Insulin & Usia & Kelas \\
\hline 1 & 100 & 80 & 130 & 200 & 64 & tidak \\
\hline 2 & 100 & 80 & 120 & 200 & 57 & tidak \\
\hline 3 & 100 & 90 & 120 & 200 & 59 & tidak \\
\hline 4 & 100 & 90 & 130 & 200 & 66 & tidak \\
\hline 5 & 100 & 80 & 120 & 200 & 53 & tidak \\
\hline 6 & 100 & 85 & 121 & 200 & 19 & tidak \\
\hline 7 & 100 & 70 & 115 & 200 & 31 & tidak \\
\hline 8 & 100 & 80 & 110 & 200 & 52 & tidak \\
\hline 9 & 100 & 73 & 122 & 200 & 44 & tidak \\
\hline 10 & 100 & 88 & 118 & 200 & 34 & tidak \\
\hline 11 & 100 & 86 & 123 & 200 & 35 & tidak \\
\hline 12 & 100 & 80 & 109 & 200 & 49 & tidak \\
\hline 13 & 100 & 70 & 135 & 200 & 62 & tidak \\
\hline 14 & 100 & 80 & 133 & 200 & 41 & tidak \\
\hline 15 & 100 & 90 & 132 & 200 & 52 & tidak \\
\hline 16 & 115 & 85 & 130 & 200 & 64 & tidak \\
\hline 17 & 123 & 77 & 113 & 240 & 65 & diabetes \\
\hline 18 & 135 & 85 & 90 & 231 & 39 & diabetes \\
\hline 19 & 100 & 90 & 130 & 210 & 62 & tidak \\
\hline 20 & 125 & 80 & 125 & 213 & 53 & diabetes \\
\hline 26 & 100 & 85 & 121 & 200 & 19 & tidak \\
\hline 27 & 100 & 70 & 115 & 200 & 31 & tidak \\
\hline 28 & 100 & 80 & 110 & 200 & 52 & tidak \\
\hline 29 & 100 & 73 & 122 & 200 & 44 & tidak \\
\hline 30 & 100 & 88 & 118 & 200 & 34 & tidak \\
\hline 31 & 100 & 86 & 123 & 200 & 35 & tidak \\
\hline 32 & 100 & 80 & 109 & 200 & 49 & tidak \\
\hline 33 & 100 & 70 & 135 & 200 & 62 & tidak \\
\hline 34 & 100 & 80 & 133 & 200 & 41 & tidak \\
\hline 35 & 100 & 90 & 132 & 200 & 52 & tidak \\
\hline 36 & 115 & 85 & 130 & 200 & 64 & tidak \\
\hline 37 & 123 & 77 & 113 & 240 & 65 & tidak \\
\hline 38 & 135 & 85 & 90 & 231 & 39 & tidak \\
\hline 39 & 100 & 90 & 130 & 210 & 62 & tidak \\
\hline 40 & 125 & 80 & 125 & 213 & 53 & tidak \\
\hline 41 & 139 & 94 & 133 & 230 & 39 & diabetes \\
\hline 42 & 80 & 75 & 108 & 200 & 28 & tidak \\
\hline 43 & 80 & 80 & 120 & 200 & 20 & tidak \\
\hline 44 & 80 & 90 & 135 & 200 & 40 & tidak \\
\hline 45 & 85 & 91 & 133 & 200 & 67 & tidak \\
\hline 46 & 80 & 91 & 132 & 200 & 52 & tidak \\
\hline 47 & 125 & 88 & 125 & 240 & 61 & diabetes \\
\hline 48 & 80 & 95 & 134 & 200 & 62 & tidak \\
\hline 49 & 88 & 95 & 135 & 200 & 46 & tidak \\
\hline 50 & 100 & 94 & 134 & 200 & 35 & tidak \\
\hline 51 & 103 & 99 & 136 & 200 & 38 & tidak \\
\hline & & & & & & \\
\hline
\end{tabular}




\begin{tabular}{|c|c|c|c|c|c|c|}
\hline 52 & 135 & 100 & 136 & 245 & 61 & diabetes \\
\hline 53 & 132 & 102 & 133 & 210 & 51 & diabetes \\
\hline 54 & 140 & 95 & 100 & 241 & 64 & diabetes \\
\hline 55 & 130 & 80 & 133 & 222 & 60 & diabetes \\
\hline 56 & 132 & 80 & 132 & 210 & 58 & diabetes \\
\hline 57 & 135 & 95 & 135 & 200 & 55 & diabetes \\
\hline 58 & 145 & 85 & 115 & 200 & 62 & diabetes \\
\hline 59 & 80 & 96 & 136 & 200 & 45 & tidak \\
\hline 60 & 136 & 85 & 96 & 200 & 57 & diabetes \\
\hline 61 & 85 & 95 & 133 & 200 & 50 & tidak \\
\hline 62 & 125 & 85 & 115 & 200 & 65 & tidak \\
\hline 63 & 100 & 102 & 140 & 200 & 52 & diabetes \\
\hline 64 & 102 & 98 & 135 & 200 & 43 & tidak \\
\hline 65 & 105 & 95 & 133 & 200 & 51 & tidak \\
\hline 66 & 100 & 95 & 131 & 200 & 66 & tidak \\
\hline 67 & 90 & 90 & 131 & 200 & 45 & tidak \\
\hline 68 & 135 & 85 & 120 & 235 & 52 & diabetes \\
\hline 69 & 135 & 91 & 135 & 200 & 63 & tidak \\
\hline 70 & 139 & 94 & 133 & 230 & 39 & diabetes \\
\hline 74 & 100 & 75 & 100 & 210 & 60 & diabetes \\
\hline 75 & 120 & 20 & 110 & 200 & 49 & diabetes \\
\hline 76 & 135 & 80 & 110 & 200 & 68 & diabetes \\
\hline 77 & 110 & 70 & 115 & 200 & 80 & diabetes \\
\hline 78 & 120 & 80 & 110 & 210 & 62 & diabetes \\
\hline 79 & 120 & 81 & 130 & 199 & 65 & diabetes \\
\hline
\end{tabular}

\section{B. Perhitungan dengan Algoritma $\mathrm{C} 45$}

Setelah proses preprocessing data akan dilakukan perhitungan menggunakan algoritma C45. Tahap pertama yang dilakukan adalah melakukan perhitungan jumlah kelas, kemudian melakukan perhitungan jumlah kasus per kelas, setelah itu mencari entropy setiap atribut lalu setelah selesai mencari entropy dilanjutkan mencari nilai gain. Nilai gain dengan nilai tertinggi merupakan akarnya kemudian cabang dan seterusnya dari keputusan kemudian di hitung kembali sampai nilai entropy seluruhnya atribut mencapai 0 maka sistem akan berhenti menghitung.

\section{Perhitungan Algoritma C45 Penyakit Hipertensi}

Pada table 4 menunjukan hasil hasil perhitungan algoritma c45 yang dilakukan oleh sistem. Sehingga nntinya akn menunjukan hasil keputusan yang berbentuk Tree Decision penyakit Hipertensi.

Jumlah data $=68$

Jumlah Hipertensi $=37$

Jumlah Aman $=31$

Entropy All $=0.994$

TABEL 5

Perhitungan Seluruh Data Training HiPERTENSI

\begin{tabular}{|l|c|c|c|c|c|}
\hline $\begin{array}{c}\text { Nilai } \\
\text { Atribut }\end{array}$ & $\begin{array}{c}\text { Jumlah } \\
\text { data }\end{array}$ & $\begin{array}{c}\text { Jumlah } \\
\text { Hipertensi }\end{array}$ & $\begin{array}{c}\text { Jumlah } \\
\text { Aman }\end{array}$ & Entropy & $\begin{array}{c}\text { Gai } \\
\text { n }\end{array}$ \\
\hline & & & & & \\
\hline $\begin{array}{l}\text { glukosa } \\
=100\end{array}$ & 42 & 23 & 19 & 0.993 & \\
\hline $\begin{array}{l}\text { glukosa> } \\
100\end{array}$ & 26 & 14 & 12 & 0.996 & \\
\hline & & & & & \\
\hline & & & & & 0 \\
\hline
\end{tabular}

\begin{tabular}{|c|c|c|c|c|c|}
\hline $\begin{array}{l}\text { glukosa< } \\
=120\end{array}$ & 49 & 30 & 19 & 0.963 & \\
\hline $\begin{array}{l}\text { glukosa } \\
>120\end{array}$ & 19 & 7 & 12 & 0.949 & \\
\hline \multirow{5}{*}{$\begin{array}{l} \\
\text { glukosa< } \\
=140 \\
\text { glukosa> } \\
140 \\
\end{array}$} & & & & & \\
\hline & & & & & $\begin{array}{l}0.03 \\
5\end{array}$ \\
\hline & 67 & 37 & 30 & 0.992 & \\
\hline & 1 & 0 & 1 & 0 & \\
\hline & 0 & & & 0 & $\begin{array}{c}0.01 \\
7\end{array}$ \\
\hline \multirow{3}{*}{$\begin{array}{l} \\
\text { diastol<= } \\
70 \\
\text { diastol }>7 \\
0 \\
\end{array}$} & 4 & 2 & 2 & 1 & \\
\hline & 64 & 35 & 29 & 0.994 & \\
\hline & 0 & & & 0 & -0 \\
\hline \multirow{3}{*}{$\begin{array}{l}\text { diastol<= } \\
80 \\
\text { diastol }>8 \\
0 \\
\end{array}$} & 22 & 5 & 17 & 0.773 & \\
\hline & 46 & 32 & 14 & 0.887 & \\
\hline & 0 & & & 0 & $\begin{array}{c}0.14 \\
4\end{array}$ \\
\hline \multirow{3}{*}{$\begin{array}{l}\text { diastol<= } \\
90 \\
\text { diastol }>9 \\
0\end{array}$} & 49 & 19 & 30 & 0.963 & \\
\hline & 19 & 18 & 1 & 0.297 & \\
\hline & 0 & & & 0 & $\begin{array}{c}0.21 \\
7 \\
\end{array}$ \\
\hline \multirow{3}{*}{$\begin{array}{l}\text { sistol<=1 } \\
10 \\
\text { sistol }>11 \\
0 \\
\end{array}$} & 9 & 0 & 9 & 0 & \\
\hline & 59 & 37 & 22 & 0.953 & \\
\hline & 0 & & & 0 & $\begin{array}{c}0.16 \\
7 \\
\end{array}$ \\
\hline \multirow{3}{*}{$\begin{array}{l}\text { sistol }<=1 \\
20 \\
\text { sistol }>12 \\
0\end{array}$} & 23 & 2 & 21 & 0.426 & \\
\hline & 45 & 35 & 10 & 0.764 & \\
\hline & 0 & & & 0 & $\begin{array}{c}0.34 \\
4 \\
\end{array}$ \\
\hline \multirow{3}{*}{$\begin{array}{l} \\
\text { sistol<=1 } \\
30 \\
\text { sistol }>13 \\
0 \\
\end{array}$} & 41 & 11 & 30 & 0.839 & \\
\hline & 27 & 26 & 1 & 0.229 & \\
\hline & 0 & & & 0 & $\begin{array}{c}0.39 \\
7 \\
\end{array}$ \\
\hline \multirow{3}{*}{$\begin{array}{l}\text { insulin<= } \\
200 \\
\text { insulin }>2 \\
00 \\
\end{array}$} & 52 & 31 & 21 & 0.973 & \\
\hline & 16 & 6 & 10 & 0.954 & \\
\hline & 0 & & & 0 & $\begin{array}{c}0.02 \\
5 \\
\end{array}$ \\
\hline $\begin{array}{l}\text { insulin<= } \\
300\end{array}$ & 68 & 37 & 31 & 0.994 & \\
\hline \multirow{2}{*}{$\begin{array}{l}300 \\
\text { insulin }>3 \\
00\end{array}$} & 0 & 0 & 0 & 0 & \\
\hline & 0 & & & 0 & 0 \\
\hline
\end{tabular}




\begin{tabular}{|c|c|c|c|c|c|}
\hline $\begin{array}{l}\text { insulin }<= \\
400\end{array}$ & 68 & 37 & 31 & 0.994 & \\
\hline \multirow[t]{2}{*}{$\begin{array}{l}\text { insulin }>4 \\
00\end{array}$} & 0 & 0 & 0 & 0 & \\
\hline & 0 & & & 0 & 0 \\
\hline usia $<=17$ & 0 & 0 & 0 & 0 & \\
\hline \multirow[t]{2}{*}{ usia $>17$} & 68 & 37 & 31 & 0.994 & \\
\hline & 0 & & & 0 & 0 \\
\hline usia $<=25$ & 3 & 0 & 3 & 0 & \\
\hline \multirow[t]{2}{*}{ usia $>25$} & 65 & 37 & 28 & 0.986 & \\
\hline & 0 & & & 0 & $\begin{array}{c}0.05 \\
2\end{array}$ \\
\hline usia $<=36$ & 11 & 1 & 10 & 0.439 & \\
\hline \multirow[t]{2}{*}{ usia $>36$} & 57 & 36 & 21 & 0.949 & \\
\hline & 0 & & & 0 & $\begin{array}{c}0.12 \\
8\end{array}$ \\
\hline usia $<=56$ & 43 & 21 & 22 & 1 & \\
\hline \multirow[t]{2}{*}{ usia $>56$} & 25 & 16 & 9 & 0.943 & \\
\hline & 0 & & & 0 & $\begin{array}{c}0.01 \\
5\end{array}$ \\
\hline
\end{tabular}

Table 5 memiliki data sebanyak 68, dari data tersebut terdapat 37 yang menderita penyakit hipertensi dan sebanyak 31 orang tidak menderita penyakit hipertensi, setelah melalui proses algoritma c45 didapat lah entropy seluruh data sebesar 0.994, kemudian di lanjutkan dengan mencari gain setiap atribut seperti yang terlihat pada table 5 hasil gain di setiap atribut selanjut akan di pilih atribut dengan gain yang tertinggi dan Atribut terpilih $=$ Sistol $<=130 \&>130$, dengan nilai gain $=0.397$ kemudian terbentuk cabang 1 dengan atribut (sistol<=130). Kemudian sistem lanjut menghitung sampai nilai pada atribut menjadi nol atau sama. Sehingga mendapat pohon keputusan seperti gambar 8

\section{Lampiran III}

Gambar 6. Pohon keputusan hipertensi

\section{Perhitungan Algoritma C45 Penyakit Diabetes}

Pada table 4.8 menunjukan hasil hasil perhitungan Entropy dan gain yang dilakukan oleh sistem. Sehingga nantinya akan menunjukan hasil keputusan yang berbentuk Tree Decision untuk penyakit diabetes.

Jumlah data $=71$

Jumlah Diabetes $=22$

Jumlah Aman $=49$

Entropy All = 0.893

TABEL 5

Perhitungan Seluruh Data Training Diabetes

\begin{tabular}{|l|c|c|c|c|c|}
\hline Nilai Atribut & $\begin{array}{c}\text { Jumlah } \\
\text { data }\end{array}$ & $\begin{array}{c}\text { Jumlah } \\
\text { Diabetes }\end{array}$ & $\begin{array}{c}\text { Jumlah } \\
\text { Aman }\end{array}$ & Entropy & Gain \\
\hline & & & & & \\
\hline glukosa $<=100$ & 41 & 2 & 39 & 0.281 & \\
\hline glukosa $>100$ & 30 & 20 & 10 & 0.918 & \\
\hline & 0 & & & 0 & 0.343 \\
\hline glukosa $<=120$ & 50 & 6 & 44 & 0.529 & \\
\hline
\end{tabular}

\begin{tabular}{|c|c|c|c|c|c|}
\hline glukosa $>120$ & 21 & 16 & 5 & 0.792 & \\
\hline & 0 & & & 0 & 0.286 \\
\hline glukosa $<=140$ & 70 & 21 & 49 & 0.881 & \\
\hline \multirow[t]{2}{*}{ glukosa $>140$} & 1 & 1 & 0 & 0 & \\
\hline & 0 & & & 0 & 0.024 \\
\hline diastol $<=70$ & 6 & 2 & 4 & 0.918 & \\
\hline \multirow[t]{2}{*}{ diastol $>70$} & 65 & 20 & 45 & 0.89 & \\
\hline & 0 & & & 0 & 0.001 \\
\hline diastol $\angle=80$ & 28 & 9 & 19 & 0.906 & \\
\hline \multirow[t]{2}{*}{ diastol $>80$} & 43 & 13 & 30 & 0.884 & \\
\hline & 0 & & & 0 & 0 \\
\hline diastol $\angle=90$ & 52 & 15 & 37 & 0.867 & \\
\hline \multirow[t]{2}{*}{ diastol $>90$} & 19 & 7 & 12 & 0.949 & \\
\hline & 0 & & & 0 & 0.004 \\
\hline sistol $<=110$ & 13 & 7 & 6 & 0.996 & \\
\hline \multirow[t]{2}{*}{ sistol $>110$} & 58 & 15 & 43 & 0.825 & \\
\hline & 0 & & & 0 & 0.037 \\
\hline sistol $<=120$ & 27 & 11 & 16 & 0.975 & \\
\hline \multirow[t]{2}{*}{ sistol $>120$} & 44 & 11 & 33 & 0.811 & \\
\hline & 0 & & & 0 & 0.02 \\
\hline sistol $<=130$ & 43 & 14 & 29 & 0.91 & \\
\hline \multirow[t]{2}{*}{ sistol $>130$} & 28 & 8 & 20 & 0.863 & \\
\hline & 0 & & & 0 & 0.002 \\
\hline insulin $<=200$ & 52 & 8 & 44 & 0.619 & \\
\hline \multirow[t]{2}{*}{ insulin $>200$} & 19 & 14 & 5 & 0.831 & \\
\hline & 0 & & & 0 & 0.217 \\
\hline insulin $<=300$ & 71 & 22 & 49 & 0.893 & \\
\hline \multirow[t]{2}{*}{ insulin $>300$} & 0 & 0 & 0 & 0 & \\
\hline & 0 & & & 0 & 0 \\
\hline insulin $<=400$ & 71 & 22 & 49 & 0.893 & \\
\hline \multirow[t]{2}{*}{ insulin $>400$} & 0 & 0 & 0 & 0 & \\
\hline & 0 & & & 0 & 0 \\
\hline usia $<=17$ & 0 & 0 & 0 & 0 & \\
\hline \multirow[t]{2}{*}{ usia $>17$} & 71 & 22 & 49 & 0.893 & \\
\hline & 0 & & & 0 & 0 \\
\hline usia $<=25$ & 3 & 0 & 3 & 0 & \\
\hline \multirow[t]{2}{*}{ usia> 25} & 68 & 22 & 46 & 0.908 & \\
\hline & 0 & & & 0 & 0.023 \\
\hline usia $<=36$ & 11 & 0 & 11 & 0 & \\
\hline \multirow[t]{2}{*}{ usia> 36} & 60 & 22 & 38 & 0.948 & \\
\hline & 0 & & & 0 & 0.092 \\
\hline usia $<=56$ & 42 & 9 & 33 & 0.75 & \\
\hline \multirow[t]{2}{*}{ usia> $>56$} & 29 & 13 & 16 & 0.992 & \\
\hline & 0 & & & 0 & 0.044 \\
\hline
\end{tabular}

Table 6 memiliki data sebanyak 71, dari data tersebut terdapat 22 yang menderita penyakit diabetes militus dan sebanyak 49 orang tidak menderita penyakit diabetes militus, setelah melalui proses algoritma c45 didapat lah entropy seluruh data sebesar 0.893, kemudian di lanjutkan dengan mencari gain setiap atribut seperti yang terlihat pada table 6 hasil gain di setiap atribut selanjut akan di pilih atribut dengan gain yang tertinggi dan Atribut terpilih adalah Glukosa <= 100 , dengan nilai gain $=0.343$, kemudian terbentuk cabang 1 dari atribut (glukosa $<=100$ ) dan seterusnya hingga nilai setiap atribut menjadi nol atau sama. Hasil pohon keputusan seperti gambar 9 berikut.

\section{Lampiran IV}

Gambar 7. Pohon keputusan diabetes 


\section{Hasil Klasifikasi}

Setelah mendapat rule / pohon keputusan kedua penyakit tersebut petugas dapat menginput data berobat pasien pada sistem data didapatkan dari pasien yang berobat pada klinik dan data pasien itu di berikan oleh dokter yang melakukan pemeriksaan. sistem menghasilkan klasifikasi seperti yang ditunjukan oleh gambar 10. Dari 30 data pasien diantaranya ada yang menderita hipeternsi, diabetes dan tidak ada sama sekali menderita penyakit keduanya. Setelah dinputkan kedalam sistem petugas dapat melakukan klasifkasi pada menu diagnose mining dan didapatkan 30 menderita hipertensi dan 4 pasien menderita penyakit diabetes. tapi hasil perhitungan akurasi ketepatan klasifikasi pada sistem untuk penyakit hipertensi menunjukan $16.667 \%$ akurasi tepat dan 83,333\% akurasi tidak tepat, kemudian pada perhitungan akurasi klasifikasi diabetes menunjukan $96.667 \%$ akurasi tepat dan $3.333 \%$ akurasi tidak tepat. Hasil perhitungan tersebut langsung di tampilkan pada grafik dihalaman dashboard, dapat dilihat pada gambar 10.

\section{Lampiran $V$}

Gambar 8. Grafik hasil klasifikasi penyakit hipertensi dan diabetes

\section{KESIMPULAN}

Berdasarkan dari tujuan penelitian ini dapat disimpulkan sistem rekam medis dalam bentuk digital sangat membantu dalam mengelolah data yang sangat banyak, membantu proses pengambilan keputusan dengan cepat, dan memudahkan klinik dalam menjalan program pengelolaan penyakit kronis (Prolanis) dari BPJS-Kesehatran. Hasil klasifikasi data mining bahwa algoritma C4.5 dapat digunakan untuk mengklasifikasi penyakit hipertensi, diabetes mellitus, tidak hipertensi, dan tidak diabetes melitus. Hasil yang ditampilkan oleh Grafik hanya menampilkan data klasifikasi penyakit hipertensi dan diabetes melitus pada bulan yang berjalan. Saran untuk penelitian selanjutnya adalah dapat menggunakan metode klasifikasi yang lain seperti Support Vector Machine (SVM), K-Nearest Neighbor (KNN), Algoritma CART (Classification and Regreesion Trees), Neural Network (NN), maupun metode klasifikasi lainnya.

\section{DAFTAR PUSTAKA}

[1] B. Kesehatan, "Panduan Praktis Prolanis," 2014. [Online]. Available: kesehatan.go.id/bpjs/dmdocuments/06-PROLANIS.pdf. [Accessed 20 Juli 2021].

[2] A. Rika, H. Kusnanto and W. Istiono, "Analisis Kesuksesan Implementasi Rekam Medis Elektronik Di RS Universitas Gadjah Mada," Jurnal Sistem Informasi, 2017.

[3] L. Pereira, R. Rijo, C. Silva and R. Martinho, "Text Mining Applied to Electronic Medical Records: A Literature Review,"
International Journal of E-Health and Medical Communications, pp. 1-18, 2015.

[4] KBBI, "KBBI Daring,” Badan Pengembangan dan Pembinaan Bahasa, Kementerian Pendidikan dan Kebudayaan Republik Indonesia, 2016. [Online]. Available: https://kbbi.kemdikbud.go.id/entri/web. [Accessed 08 Februari 2021].

[5] A. J. N. Susanto, Klasifikasi Penyakit Diabetes Mellitus Menggunakan Algoritma Decision Tree C4.5, Batam: Politeknik Negeri Batam, 2018.

[6] M. S. Efendi and H. A. Wibawa, Prediksi Penyakit Diabetes Menggunakan Algoritma ID3 dengan Pemilihan Atribut Terbaik, vol. VI, Purwokerto: JUITA, 2018, pp. 1-8.

[7] F. Hermawati, Data Mining, Yogyakarta: Andi, 2013.

[8] F. S. Sulaeman and M. A. Rilmansyah, "Aplikasi Penerapan Algoritma C45 untuk Memprediksi Kelulusan," Jurnal Media Teknik \& Sistem Industri, vol. 5, pp. 41-54, 2021.

[9] K. RI, Pusdatin Hari Hipertensi Sedunia, Jakarta Selatan: Kementrian Kesehatan RI, 2014, pp. 1-8.

[10] K. RI, Pusdatin Hari Diabetes Sedunia, Jakarta Selatan: Kementrian Kesehatan RI, 2018. 
Journal of Applied Informatics and Computing (JAIC)

Vol.5, No.1, Juli 2021, pp. 74 86

e-ISSN: 2548-6861

Lampiran I. Use Case Diagram

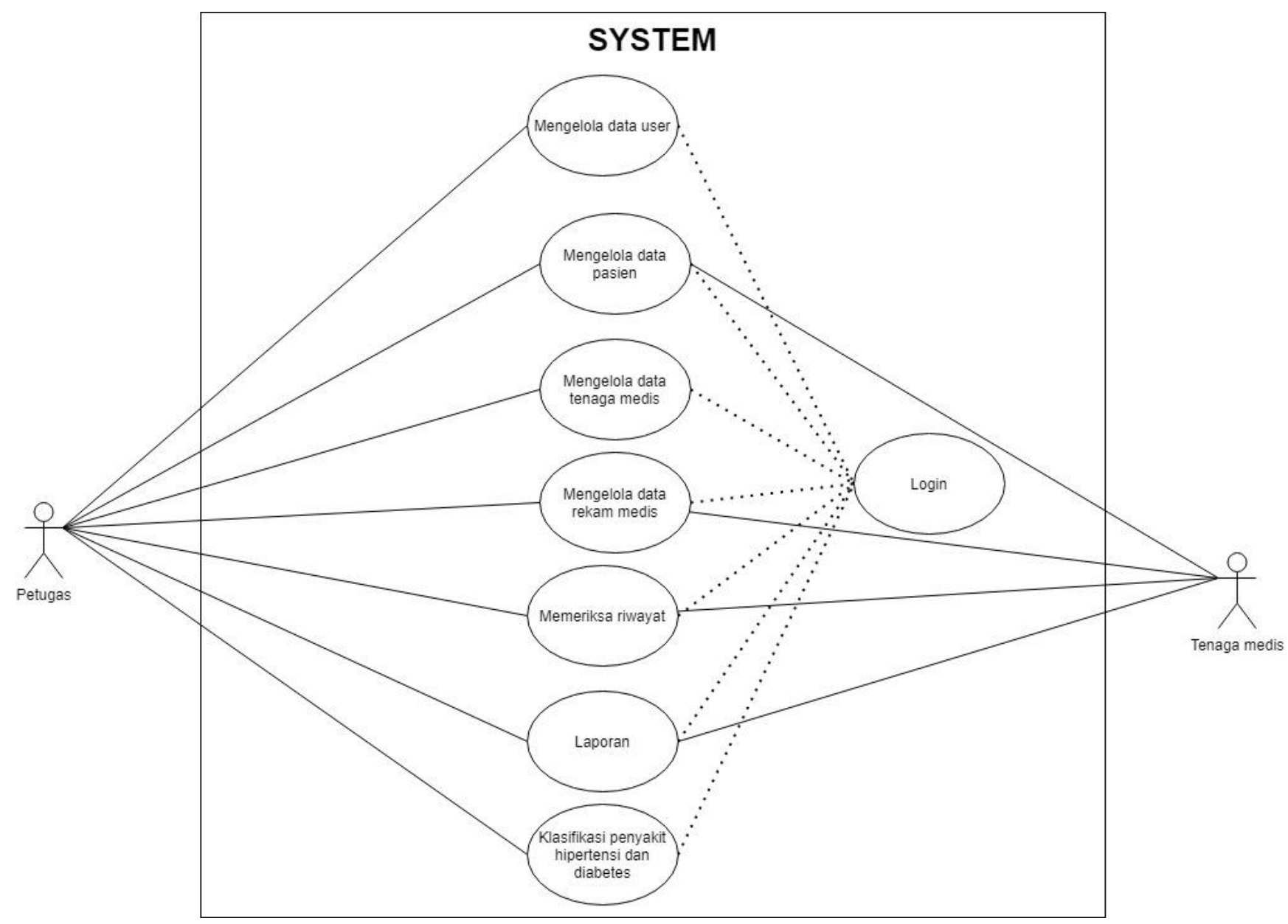


Lampiran II. ER-Diagram
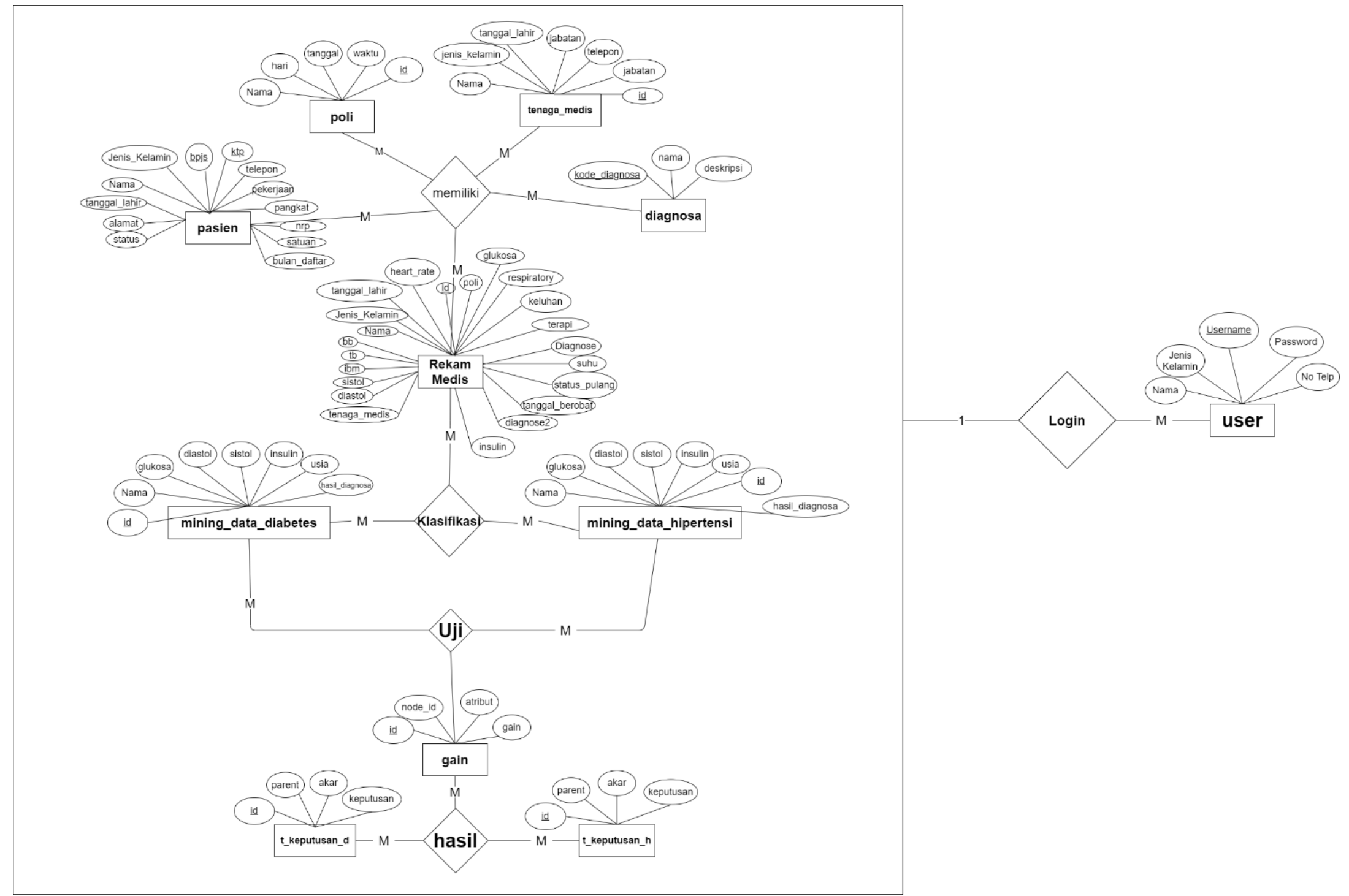

JAIC Vol. 5, No. 1, Juli 2021: $74-86$ 
Lampiran III. Rule Hipertens

Rule Hipertensi

HIDE TABLE

No PARENT

1 (sistol 130 ) AND (diastolk $=80$ )

(sistol) 130) AND (diastolk=80)

$3 \quad$ (sistol 130$)$

\section{Lampiran IV. Rule Diabetes}

Rule Diabetes

\section{HIDE TABLE}

No PARENT

(glukosa $<=100$ ) a

(glukosa $<100)$ AND (insulin 2200$)$

(glukosa $<=100)$ AND (insulin 200)

(glukosa>100) AND (insulin $<=200$ ) AND (sistolk=120

(glukosa>100) AND (insulin $<200$ ) AND (sistol=120) AND (diastol>80) AND (glukosa $<=140$ )

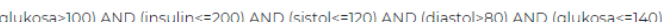

(glukosa 100 ) AND (insulin $<=200$ ) AND (sistol<=120) AND (diastol> 80$)$

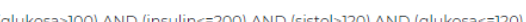

(glukosa>100) AND (insulin $=200$ ) AND (sistol>120) AND (glukosa $\alpha=120$ )

(glukosa>100) AND (insulin>200) AND (sistolk=130)

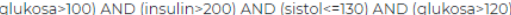

(glukosa>100) AND (insulin>200) AND (sistolk=130) AND (glukosa>120) AND (diastol>80) AND (sistol=110

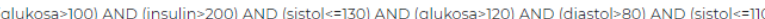

(glukosa 100) AND (insulin>200) AND (sistolk=130) AND (glukosa>120) AND (diastol>80)

(glukosa>100) AND (insulin>200
ROOT

(glukosar $=100)$

|glukosa $>100$

(diastol>80)
DECIIION

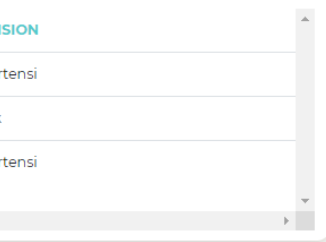

\begin{tabular}{|c|c|}
\hline RоOт & DECISION \\
\hline (diastol<=90) & tidak \\
\hline (diastol=80) & diabetes \\
\hline (diastol>80) & tidak \\
\hline (diastol<=80) & diabetes \\
\hline (sistol=110) & diabetes \\
\hline (sistol>1>10) & tidak \\
\hline (glukosa $>140$ ) & diabetes \\
\hline (diastol<=90) & tidak \\
\hline (diastol-90) & tidak \\
\hline (glukosa $=120)$ & diabetes \\
\hline (diastol<=80) & diabetes \\
\hline (diastol<=90) & diabetes \\
\hline (diastol>90) & diabetes \\
\hline (sistol>1>10) & diabetes \\
\hline$($ Sistol>130) & diabetes \\
\hline
\end{tabular}

Klasifikasi Penyakit Hipertensi Dan Diabetes Berbasis Web Pada Klinik Pratama Rumkitban 01.08.03 Batam (Mira Chandra Kirana dan Michel K) 
Lampiran V: Hasil Klasifikasi

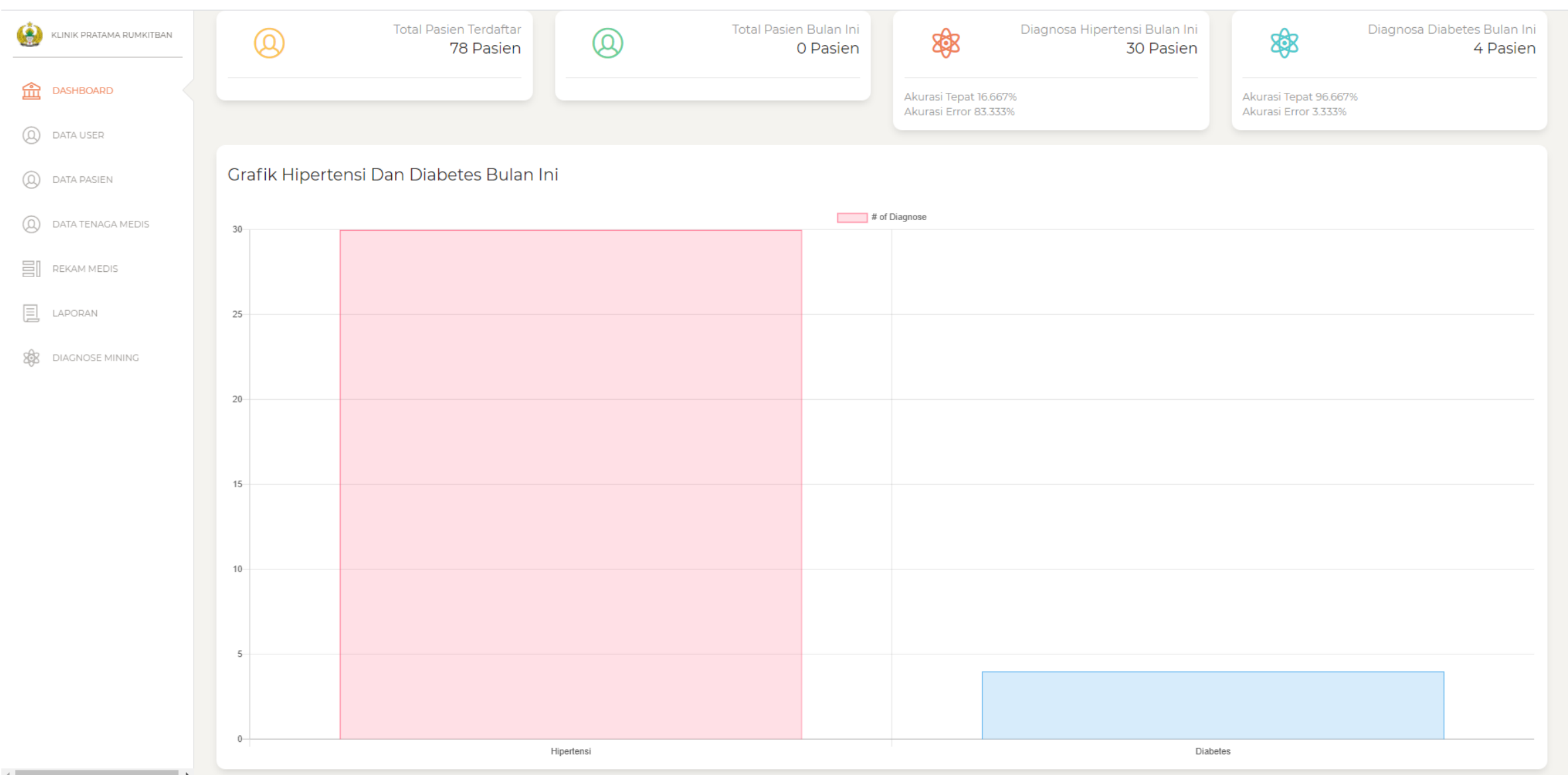

